\title{
SYNTHETIC GEM MATERIALS IN THE 2000S: A DECADE IN REVIEW
}

\author{
Nathan Renfro, John I. Koivula, Wuyi Wang, and Gary Roskin
}

\begin{abstract}
The first decade of the 2000s brought a constant flow of previously known synthetics into the marketplace, but little in the way of new technology. The biggest development was the commercial introduction of faceted single-crystal gem-quality CVD synthetic diamonds. A few other interesting and noteworthy synthetics, such as Malossi hydrothermal synthetic emeralds and Mexifire synthetic opals, also entered the market. Identification of synthetic gem materials continued to be an important function of-and, in some cases, challenge for-gemologists worldwide.
\end{abstract}

T he development of synthetics and the methodologies used to detect new and existing materials is of great importance to the international gem community. Indeed, whether a synthetic gem was grown in the 2000s or the 1880s, today's gemologists must still be prepared to deal with it. Many synthetic gems were prominent in the marketplace in the first decade of the 2000s (see, e.g., figure 1).

The decade also saw some new synthetics. Among the synthetic colored stones introduced was the Malossi hydrothermal synthetic emerald (Adamo et al., 2005), which was gemologically similar to both Russian synthetic emeralds and those manufactured by Linde-Regency in the United States. Also new to this decade was a synthetic fire opal marketed as Mexifire (Choudhary and Bhandari, 2008). On initial examination, this nonphenomenal synthetic opal resembled manufactured glass.

Yet it is clear from the overall volume of pub-

See end of article for About the Authors and Acknowledgments. Gems \& Gemologr, Vol. 46, No. 4, pp. 260-273.

(c) 2010 Gemological Institute of America lished literature that the most significant developments-and the focus of most research-during this decade involved the production of gem-quality synthetic diamonds, primarily those grown by the comparatively new CVD (chemical vapor deposition) process. Who can forget the September 2003 cover of Wired magazine, with a diamond-pavéd "supermodel" next to the headlines "\$5 a carat. Flawless. Made in a lab."? This article proclaimed that "The diamond wars have begun," and touted the potential for outright cheap but extremely high-quality colorless and fancy-colored synthetic diamonds grown by two very different processes (CVD and HPHT). Although neither of these technologies was new to the 2000s - and neither has even approached a price as low as $\$ 5$ a carat-both made important commercial statements and had a major impact on the diamond trade and gemological research during this first decade.

It is important to state that reviews such as this can serve only as guides to the available gemological literature. Anyone seeking in-depth information regarding synthetic gems and their identification 


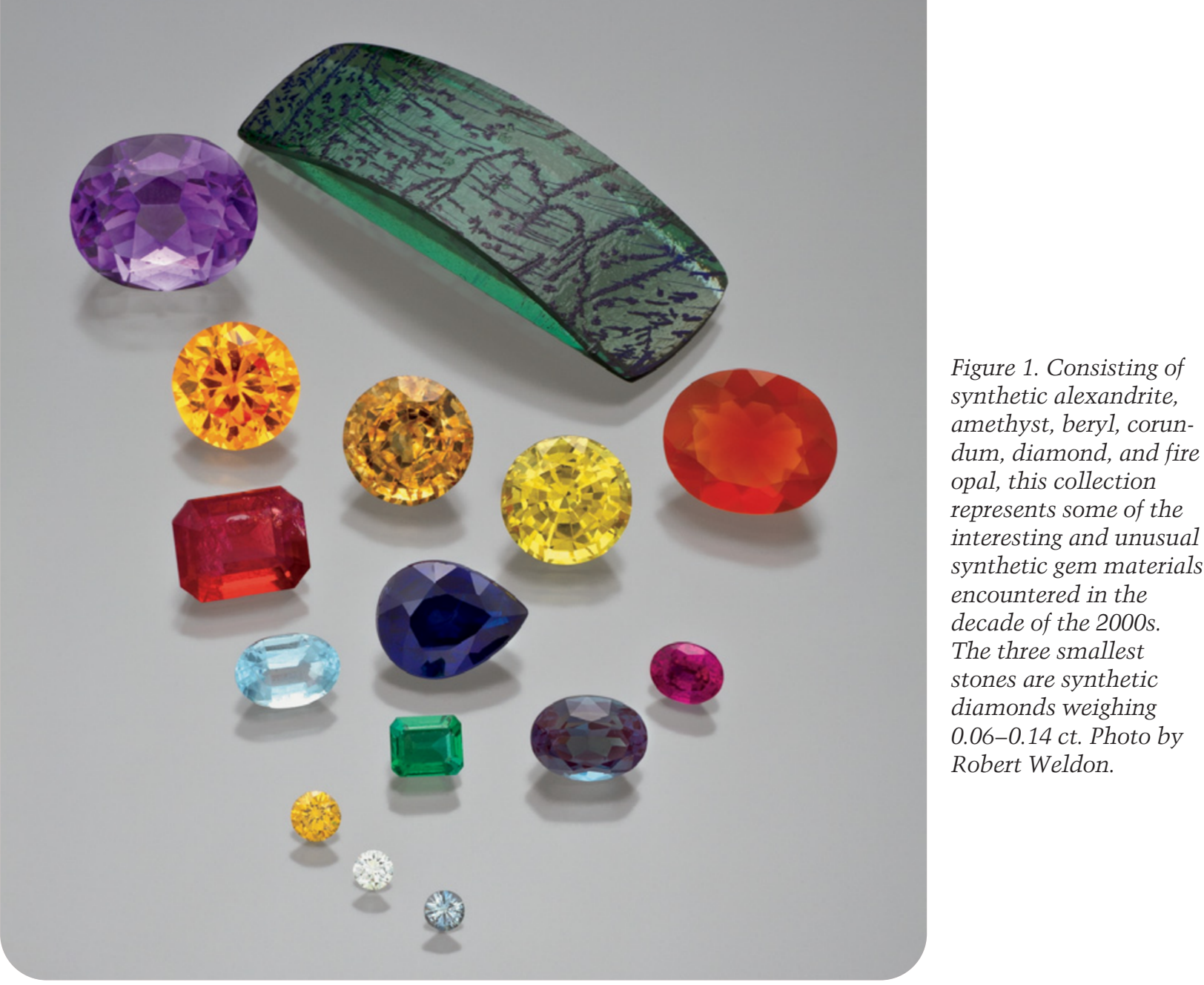

should consult the references at the end of the article to gain the knowledge required to recognize and correctly identify the various materials under discussion. In addition, useful reviews of synthetic materials that have impacted the gem trade were previously published in Gems «) Gemology (Nassau, 1990; Koivula et al., 2000) and in Elements magazine (Kane, 2009), while the largest collection of images detailing inclusions and other microfeatures in gemologically significant synthetics can be found in the three volumes of the Photoatlas of Inclusions in Gemstones (Gübelin and Koivula, 1986, 2005, 2008).

It should also be noted that only those synthetic products that are actually new to the prior decade are included in this review. For example, although hydrothermally grown cobalt-colored synthetic blue quartz was described in the Winter 2008 issue of Gems $\leftrightarrow$ Gemology (Choudhary, 2008), it is actually a material that was introduced in the 1990s (see Koivula et al., 1993), so it was not included in this retrospective.

\section{SYNTHETIC DIAMOND}

Synthetic diamonds were an important concern throughout the past decade, although supplies of gem-quality material were never extensive, and fashioned synthetic diamonds were only occasionally submitted for diamond grading reports. In the GIA Laboratory, for example, gem-quality synthetic diamonds have been seen only rarely (a fraction of a percent of the large volume of diamonds examined daily), and the vast majority have had a (fancy) bodycolor. Kitawaki et al. (2008) of the GAAJ-Zenhokyo Laboratory in Tokyo reported identifying more than 100 yellow synthetic melee diamonds (smaller than $0.20 \mathrm{ct}$ ) among material received for identification over the course of four months, a significant amount but still a small portion of the total number of melee stones examined.

The big shift between the 1990s and the 2000s came in the processes used to synthesize diamonds. In the 1990s, synthetic diamonds grown by the application of both high pressure and high temperature in molten iron/nickel fluxes (the HPHT process) were of primary concern. Such lab-grown diamonds produced today are still commonly yellow to brownish orange as grown (due to nitrogen; Shigley et al., 2002), but they can also be grown with a blue body- 
color and treated to pink (Shigley et al., 2004). While the quality, quantity, and size of these synthetics have increased over the past decade-with the largest faceted HPHT synthetic diamond submitted to the GIA lab being 4.09 ct (Wang and Moses, 2010) - the detection methods used to separate them from natural diamonds have remained essentially the same.

Early in the decade, companies like Gemesis Corp. in Sarasota, Florida, began to produce and market HPHT-grown synthetic diamonds, primarily in shades of yellow to orange (again, see Shigley et al., 2002). Chatham Created Gems began to sell their own branded HPHT-grown stones in a variety of colors (again, see Shigley et al., 2004), such as blue, yellow, and pink. It was CVD synthesis by Apollo Diamond, however, that caused the largest stir in the trade.

The CVD method involves bringing together the needed gaseous reagents - typically a small amount of methane $\left(\mathrm{CH}_{4}\right)$ in hydrogen $\left(\mathrm{H}_{2}\right)$-in a chamber with a substrate. A reaction among these components is initiated at high temperatures and low pressures. The reactants, products, and reactive species are transported throughout the chamber by diffusion and convection. Over the substrate surface, various reactions (adsorption, diffusion, and desorption) occur among the chemical species, leading to the deposition of synthetic diamond and, ultimately, the growth of a continuous layer of material (Butler and Woodin, 1993; Davis, 1993; Spear and Dismukes, 1994, Butler et al., 2009). When a diamond (natural or synthetic) is used as the substrate, single-crystal CVD gem-quality synthetic diamond can be produced.

The first successful and reproducible growth of synthetic diamond as a thin film using a CVD technique was achieved by W. G. Eversole in 1952 (Kiffer, 1956, as referenced in Angus, 1994). It is interesting to note that this event predated General Electric's 1955 announcement that its researchers had created single-crystal synthetic diamonds by the HPHT method (Bundy et al., 1955, as referenced in Angus, 1994). However, the early CVD products were exclusively polycrystalline (and, therefore, not gem quality), and the first single-crystal CVD-grown synthetic diamonds were extremely small (on the order of a few micrometers). Not until 1993 did Badzian and Badzian report the growth of singlecrystal CVD synthetic diamond as thick as $1.2 \mathrm{~mm}$; subsequently, several other groups (e.g., Doering and Linares, 1999; Linares and Doering, 1999) reported

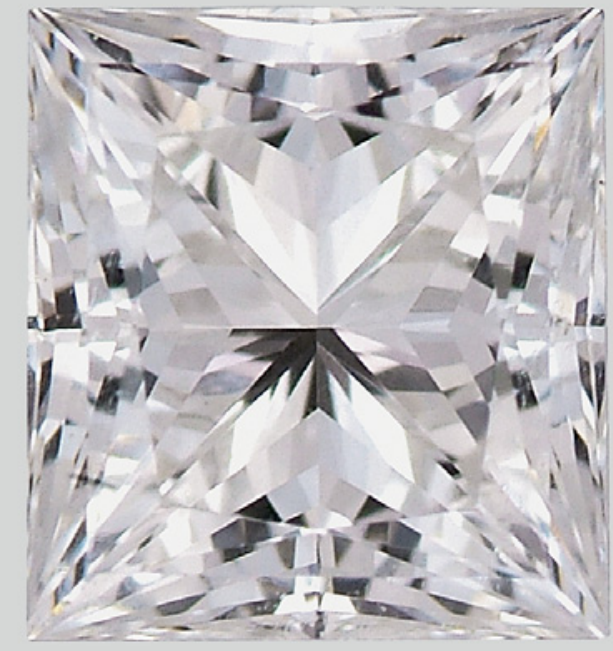

Figure 2. This near-colorless synthetic diamond $(0.30 \mathrm{ct}$ ) illustrates the improvements in color and clarity seen in the later CVD-grown products offered by Apollo Diamond. Photo by Jian Xin Liao.

the CVD growth of undoped and boron-doped singlecrystal synthetic diamond of approximately $1 \mathrm{~mm}$ thickness.

Early in the 2000s, however, Wang et al. (2003) reported on the gemological and spectroscopic properties of 15 CVD synthetic diamonds from Apollo Diamond; only a few were faceted. As a common feature, these samples had a limited thickness or depth $(0.6-2.5 \mathrm{~mm})$ and all displayed varying saturation of a brown hue. The faceted samples were small (<0.30 ct) and contained abundant cleavage cracks and pinpoint-sized black inclusions. Martineau et al. (2004) described the experimental CVD products from De Beers. More than a thousand samples (produced for research purposes only) were studied for that report, including high-purity type IIa colorless, brown, pink, and boron-doped type IIb blue synthetic diamonds. The faceted goods ranged from $\sim 0.3$ to 2.6 ct, with clarities varying from IF to $\mathrm{I}_{3}$. Since then, significant improvements in the CVD growth technique and, consequently, crystal quality have been reported (Yan et al., 2004; Tallaire et al., 2005; Wang et al., 2005; Miyatake et al., 2007).

Wang et al. (2007) analyzed the gemological and spectroscopic properties of 43 samples of Apollo's later production (figure 2), which showed major improvements in size, color, and clarity. In addition to colorless and near-colorless material, fancy orangeto-pink hues were produced-comparable in color 


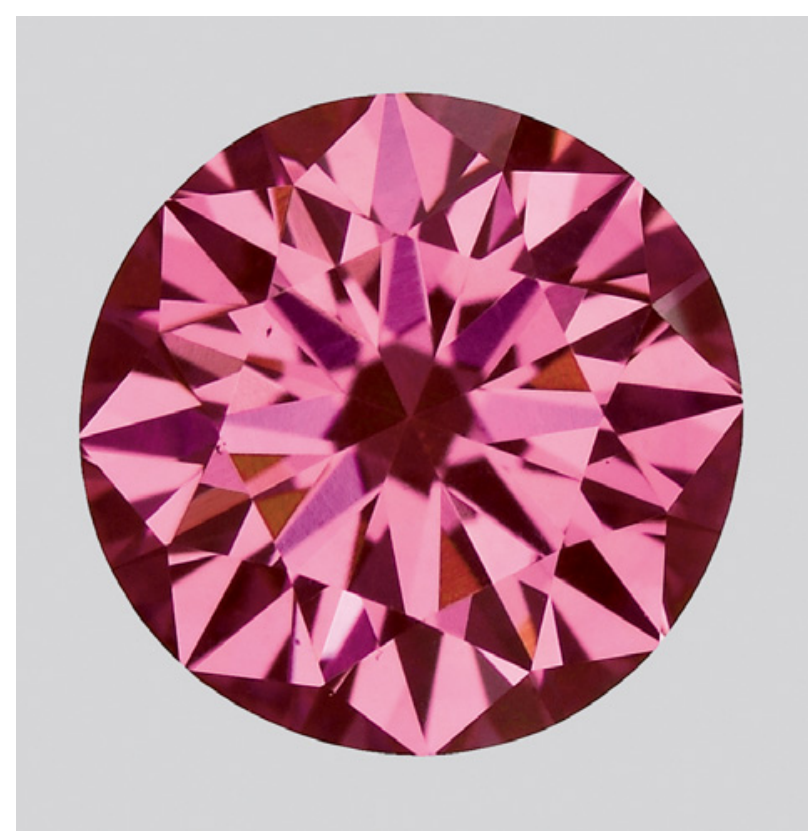

Figure 3. This $0.61 \mathrm{ct}$ round brilliant from Apollo Diamond is an example of the strongly colored pink synthetic diamonds now being produced by the CVD method. Photo by Jian Xin Liao.

and clarity to natural diamonds. These colors were attributed to a broad absorption band at $\sim 520 \mathrm{~nm}$, which has not yet been observed in natural diamonds and is distinctly different from the $550 \mathrm{~nm}$ band seen

Figure 4. Although they are also observed in some natural diamonds, high-order interference colors are considered an indicator of CVD-grown synthetic diamonds, as is the case with the sample illustrated here. Photomicrograph by Jian Xin Liao; magnified 46x.

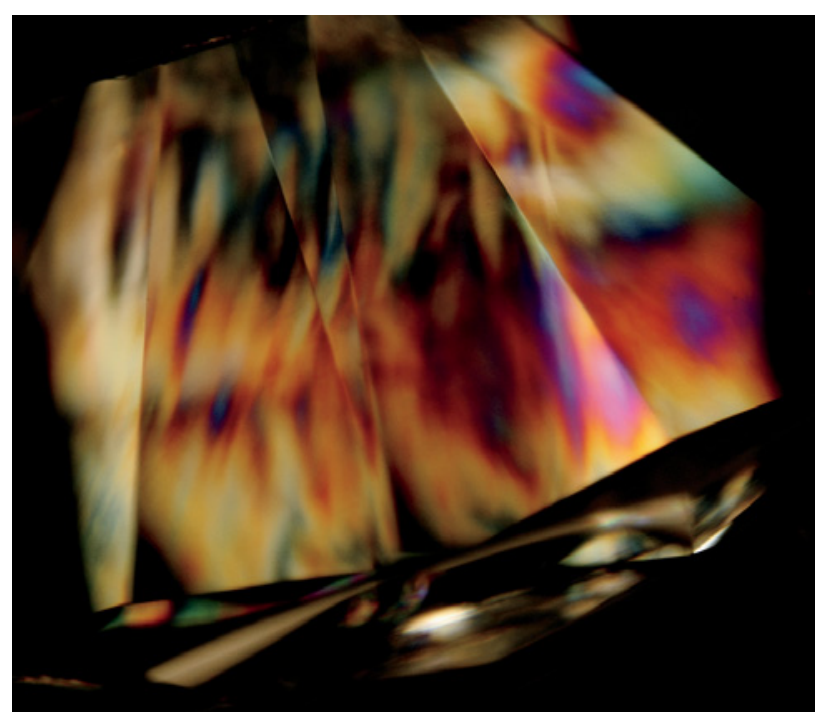

in natural pinks. More recently, Apollo Diamond introduced strongly colored pink CVD synthetic diamonds (Wang et al., 2010; figure 3), with relatively high concentrations of nitrogen-vacancy (NV) centers. These were color graded mainly as Intense to Vivid pink, and weighed $~ 0.3-0.7 \mathrm{ct}$.

It is important to note that-though still quite rare-faceted CVD-grown diamonds are being traded in the jewelry market, with a few having been identified in gem laboratories during routine testing (e.g., Chadwick, 2008; Chadwick and Breeding, 2008; Wang, 2009; Kitawaki et al., 2010; Wang and Johnson, 2010). A near-colorless faceted CVD synthetic diamond weighing over 1 ct was identified recently by the GIA lab (Wang and Moe, 2010).

CVD synthetic diamonds can be identified through careful attention to their gemological and spectroscopic properties. While not conclusive, several gemological observations serve as good indications: strong internal graining with an indistinct "fuzzy" appearance, high-order interference colors (figure 4), and the presence of pinpoints. These gemological features do, however, appear in some natural diamonds as well.

Early products from Apollo with varying saturations of brown color displayed a weak orange fluorescence to UV radiation that was considered a useful indication of CVD synthesis (Roskin, 2003; Wang et al., 2003; Martineau et al., 2004). However, this feature is absent from most of the new products. Fluorescence and phosphorescence images obtained with the DTC DiamondView continue to be very useful for the identification of CVD synthetic diamonds. In particular, orange fluorescence with irregularly patterned areas of blue fluorescence, as well as narrow growth bands, appear to be characteristic when they are present. Spectroscopic features are very important for CVD synthetic diamond identification. The $3123.5 \mathrm{~cm}^{-1}$ absorption in the midinfrared region, strong emissions from NV centers, the 596/597 $\mathrm{nm}$ doublet emission, and the doublet $[\mathrm{Si}-\mathrm{V}]^{-}$emission at 736.6 and $736.9 \mathrm{~nm}$ are very useful (figure 5).

LifeGem Synthetic Diamonds. One synthetic diamond innovation the trade likely did not expect was announced by LifeGem (now LifeGem Created Diamonds), of Elk Grove Village, Illinois, in 2003 (Laurs and Overton, 2003). In 2004 during an Accredited Gemologists Association panel in Tucson, Arizona, Alex Grizenko of Lucent Diamonds stated that LifeGem diamonds were being processed from 

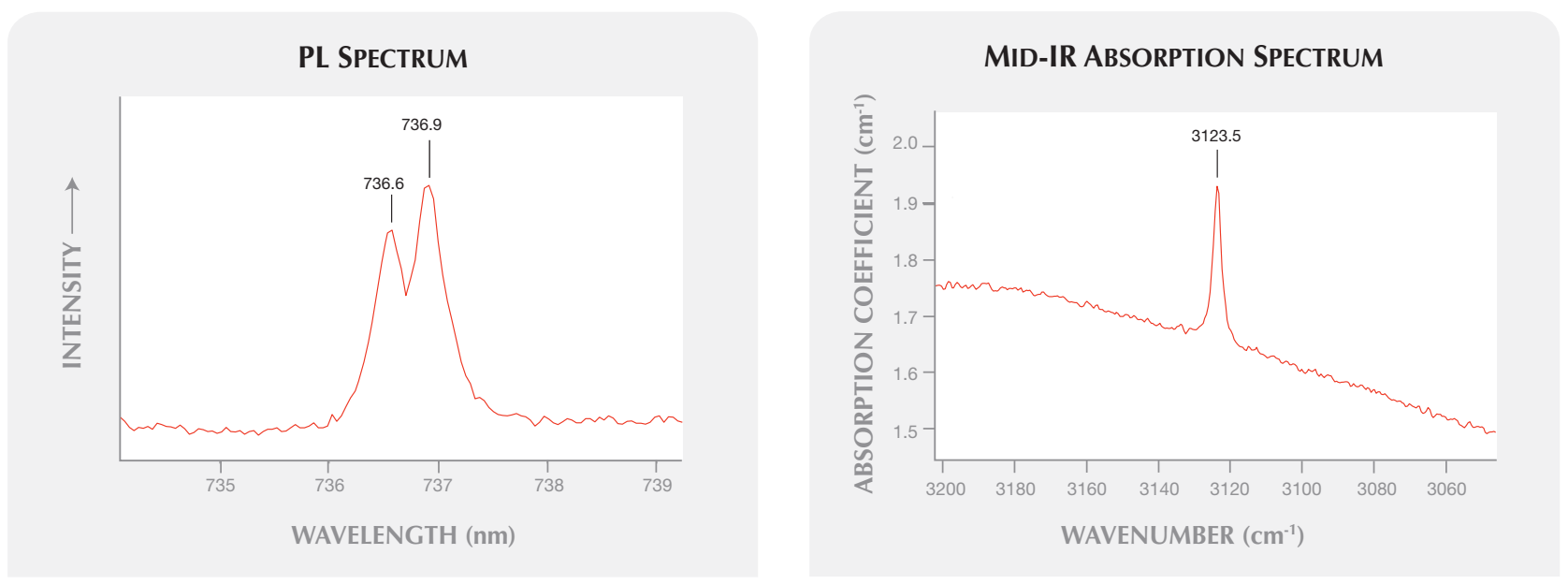

Figure 5. Absorption at $3123.5 \mathrm{~cm}^{-1}$ in the mid-IR region (right), strong emissions from NV centers, a 596/597 nm doublet, and another doublet at 736.6 and $736.9 \mathrm{~nm}$ (left) are currently very useful features in the identification of CVD-grown diamonds.

"100\% cremated carbon" (Roskin, 2004). When a person decides in advance to undergo the LifeGem process, a special cremation procedure preserves enough carbon to grow the diamond. In other cases, LifeGem needs to add carbon to complete the gem, as ash from traditional cremation doesn't retain enough for the diamond growth process (Grahm, 2003). The company reported having partners in the mortuary business worldwide and produced $\sim 1,000$ diamonds annually. Dean VandenBiesen, one of the company's founders, said they used $8 \mathrm{oz}$. $(227 \mathrm{~g})$ of cremated remains to

Figure 6. Possibly resulting from autoclave contamination, phantom planes consisting of dark blue crystallites of copper chloride were observed for the first time in Russian hydrothermal synthetic rubies. Photomicrograph by I. I. Koivula; magnified 20x.

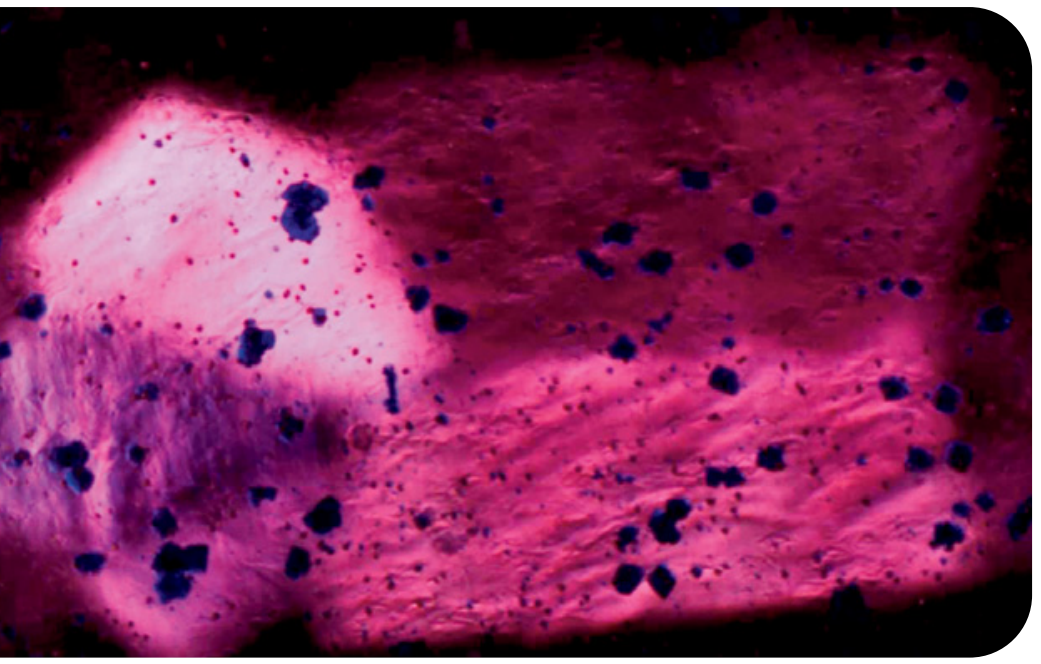

retrieve the carbon needed to grow one LifeGem synthetic diamond (pers. comm., 2004). From those who are not being cremated but prepared for burial, Mr. VandenBiesen indicated that $\sim 40 \%$ of the carbon needed for a LifeGem was retrieved from a $5 \mathrm{~g}$ sample of the deceased's hair.

A Worried Trade. While the gem industry was well aware of the commercial advances in gem-quality synthetic diamonds, it was September 2003 when the consumer was thrust into the mix. But the news was not passed through the jewelry trade-it came from a story in the technology magazine Wired (Davis, 2003).

Davis's "The New Diamond Age" article was a well-researched and entertaining docudrama: "Armed with inexpensive, mass-produced gems, two startups are launching an assault on the De Beers cartel." JCK's senior diamond editor Rob Bates (2003) later wrote, "Wired magazine sent shock waves through the industry .... The story on diamond synthetics covered mostly familiar territory for the industrybut its sensational tone caused some to worry."

The article described a concerned "Antwerp dealer," who was quoted as saying that "unless [CVD synthetics] can be detected, they will bankrupt the industry." Davis also noted "a De Beers executive" who had "gone pale and hands shaking" at the thought of mass-produced synthetic gem-quality diamonds. The Wired feature did give consumers their first glimpse of Gemesis' HPHT and Apollo's CVD gem-quality synthetic diamonds, even going so far as to mention their potential future use as a replacement for silicon in computer microprocessors. As noted above, how- 


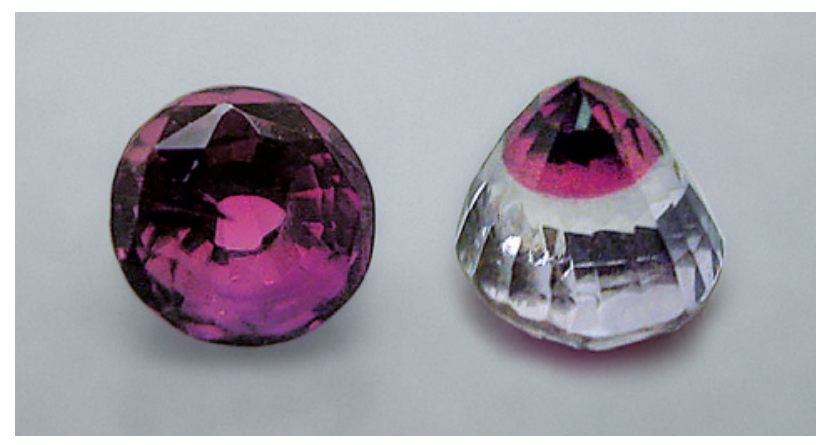

Figure 7. To produce a novelty, flame-fusion synthetic rubies and sapphires can be easily cut from areas within a boule where near-colorless portions join with the colored overgrowths. When this is done, a strongly color-zoned synthetic is the result, as shown by this $1.05 \mathrm{ct}$ example. Composite photo by H. A. Hänni, (c SSEF.

ever, well-equipped gemological laboratories can identify all synthetic diamonds, and the "\$5 a carat" flawless lab-grown diamond remains a journalist's attention grabber - with no basis in the marketplace.

\section{SYNTHETIC RUBY}

No new types of synthetic rubies were introduced into the gem trade in the past decade. However, there were reports of interesting internal features in previously known and well-documented products. One of these inclusions consisted of phantom planes in Russian hydrothermal synthetic rubies that were randomly dusted with intense dark blue crystallites (figure 6) of transparent-to-translucent copper chlo-

Figure 8. Containing numerous glass-filled surfacereaching cracks, this $3.50 \mathrm{ct}$ flame-fusion synthetic ruby illustrates that synthetics can be treated, and that the presence of a treatment should not be construed as indicating natural origin. Photo by Robert Weldon.

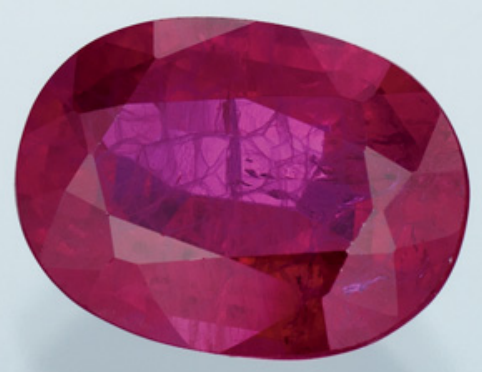

ride (Gübelin and Koivula, 2005). In theory, it is possible that the precipitation of these crystals resulted from contamination, perhaps caused by a small "leak" through the inert metal lining in a copper containment vessel.

Another unusual sample was a strongly colorzoned flame-fusion synthetic ruby that had been faceted into an off-round oval mixed cut with a purplish red color zone located near the culet (figure 7). In face-up position, this synthetic appeared purplish red, even though the bulk of the material, including most of the pavilion and the entire crown, was actually very pale blue to almost colorless (Kiefert et al., 2004). It is not known if the original crystal was intentionally grown to be strongly color zoned or whether this was an accident of the growth process. In the past, flame-fusion synthetic rubies and sapphires have been grown using colorless synthetic corundum rods as "seeds." Synthetic gems could be cut from those areas where the near-colorless portions join with the colored overgrowth.

A continuing problem for gemologists is the many treated synthetics in the marketplace-and the risk they could be misidentified as treated natural stones. One such synthetic product is lead glass-filled flame-fusion synthetic ruby (see, e.g., figure 8). Jang-Green and Befi (2007) reported on a 12.84 ct sample that was apparently quench crackled to induce surface-reaching fractures, and those frac-

Figure 9. With immersion microscopy, curved striae were spotted in this quench-crackled, lead glass-filled $12.84 \mathrm{ct}$ flame-fusion ruby, which readily served to identify it as a synthetic. Photomicrograph by Riccardo Befi and HyeJin Jang-Green; magnified 40x.

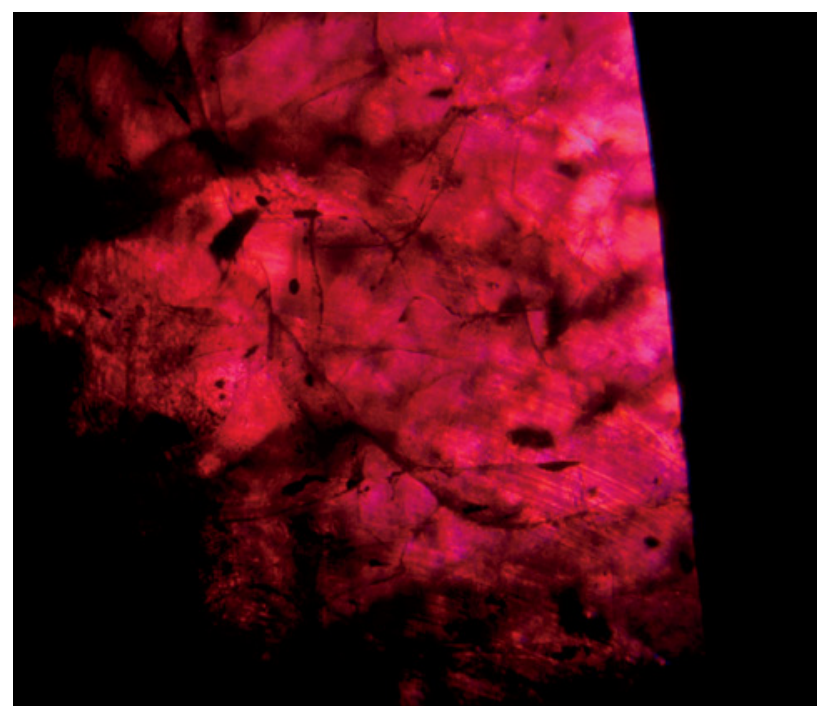



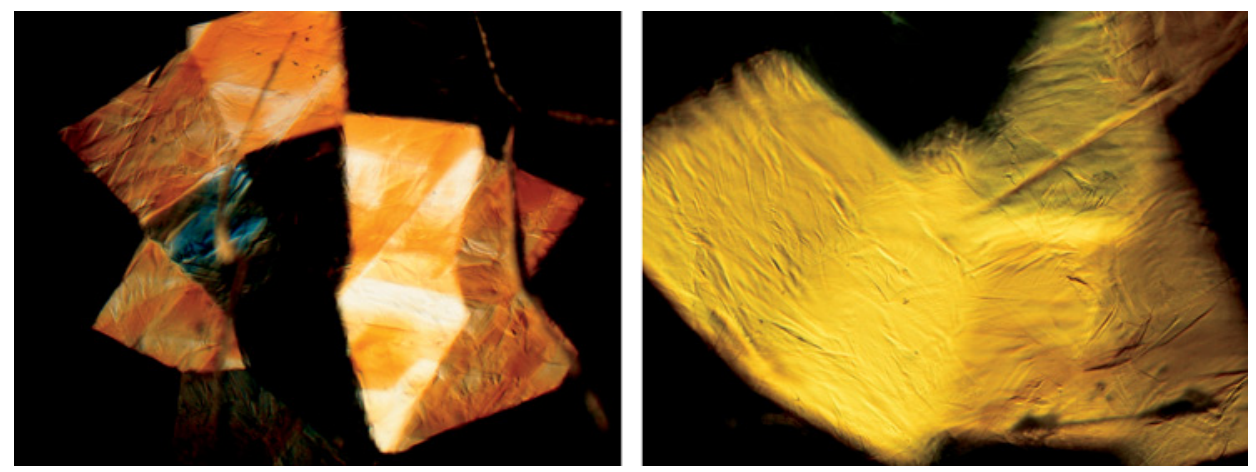

Figure 10. Distinctive roiled-to-angular growth structures, sometimes described as chevron shaped, make hydrothermally grown yellow synthetic sapphires relatively easy to identify. Photomicrographs by J. I. Koivula; magnified 15x and $40 x$.

tures were then filled with lead glass to reduce their visibility. When the sample was examined with immersion, curved striae readily identified it as a synthetic (figure 9). Relatively inexpensive, highquality flame-fusion and Czochralski-pulled synthetics are available in large quantities, so it is not too surprising that they would be subjected to treatments of all types, including glass infilling. Therefore, it is important to identify not only the presence of a treatment, but also the natural or synthetic origin of the starting material to which that treatment has been applied.

\section{SYNTHETIC SAPPHIRE}

Hydrothermal synthetic sapphires grown in Russia continued to be available, in colors other than the normally expected blue. The Gem Testing Laboratory in Jaipur, India, examined $\sim 20$ faceted synthetic yellow sapphires that proved to be grown by the hydrothermal method (Choudhary, 2005). They ranged from 3.50 to $5.30 \mathrm{ct}$ and had characteristic inclusions such as scattered flake-like "breadcrumbs"

Figure 11. This $0.91 \mathrm{ct}$ bluish green flame-fusion synthetic sapphire displayed a bodycolor and inclusions the GIA Laboratory had never encountered before. Photo by Robert Weldon.

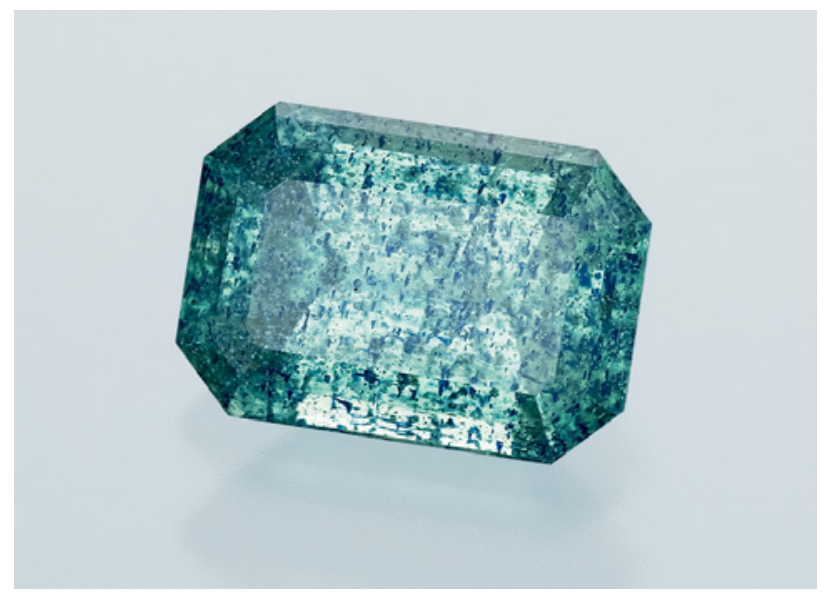

and distinctive roiled-to-angular growth structures (figure 10) sometimes described as chevron-shaped.

As with synthetic rubies, unusual internal features were also observed in synthetic sapphires during this decade. Koivula et al. (2008) reported on bluish green flame-fusion synthetic sapphires (e.g., figure 11) that contained numerous vibrant blue solid inclusions, as well as the more expected rounded and distorted gas bubbles (figure 12). Because of their color, the inclusions were suspected to contain cobalt. Indeed, a very weak visible-light absorption spectrum attributed to cobalt was detected with a standard gemological spectroscope. Raman analysis could not conclusively identify these isotropic inclusions, but it suggested that they were related to spinel.

\section{SYNTHETIC EMERALD AND OTHER BERYLS}

Available in the gem trade since 2004, the Malossi product (reportedly grown in the Czech Republic using Italian technology) was the only new develop-

Figure 12. Associated with the gas bubbles more typical of flame-fusion material, these cobalt-colored blue inclusions in the synthetic sapphire in figure 11 could not be conclusively identified. Photomicrograph by J. I. Koivula; magnified 25x.

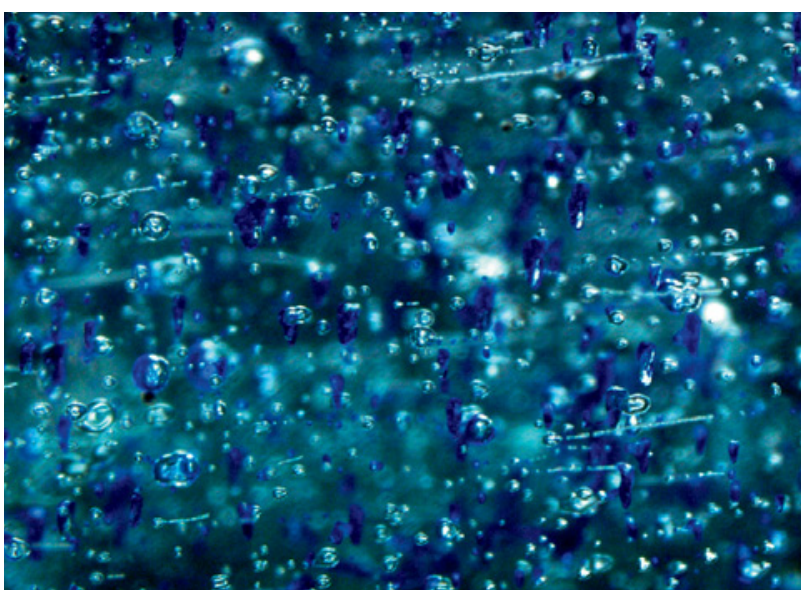



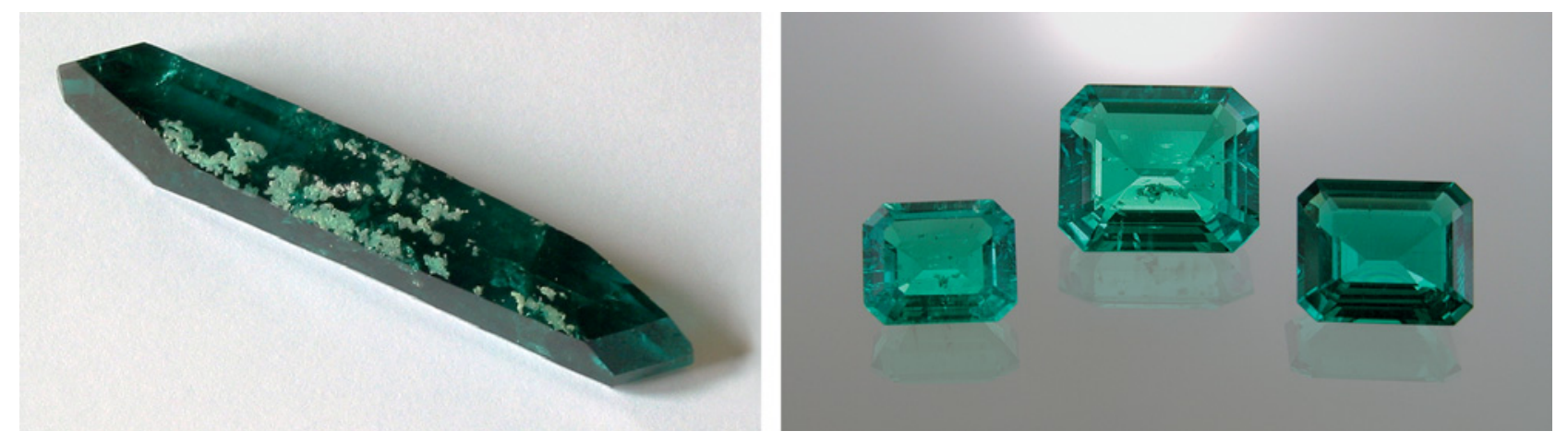

Figure 13. Malossi hydrothermal synthetic emeralds have been available in the trade since 2004. The rough specimen on the left ( 6 cm long) is partially encrusted with white synthetic phenakite crystallites. Photos by Ilaria Adamo.

ment in the area of synthetic emeralds in the 2000s (see figure 13 and Adamo et al., 2005). This is believed to be a new type of synthetic emerald colored only by $\mathrm{Cr}^{3+}$. The highly diagnostic growth structures normally encountered in hydrothermally grown material were all but absent from the samples examined. Nevertheless, the reported growth method is similar to that described for other hydrothermal synthetic emeralds: that is, use of a natural beryl seed plate in an autoclave. The producer indicated that hydrochloric acid is used to prevent $\mathrm{Cr}$ from precipitating out of the solution so it can instead be incorporated into the crystals (Adamo et al., 2005); features in the mid-IR spectrum are consistent with this statement.

Separation of the Malossi product from natural emerald is relatively straightforward. Irregular growth features, a seed plate, and synthetic phenakite-like crystals (figure 14) all readily indicate synthetic origin. Chemically, the presence of $\mathrm{Cl}$ concentrations greater than $0.2 \mathrm{wt} . \%$ and the absence of additional

Figure 14. A cluster of small inclusions, probably synthetic phenakite, were observed in this Malossi hydrothermal synthetic emerald. Photomicrograph by Renata Marcon; magnified 50x.

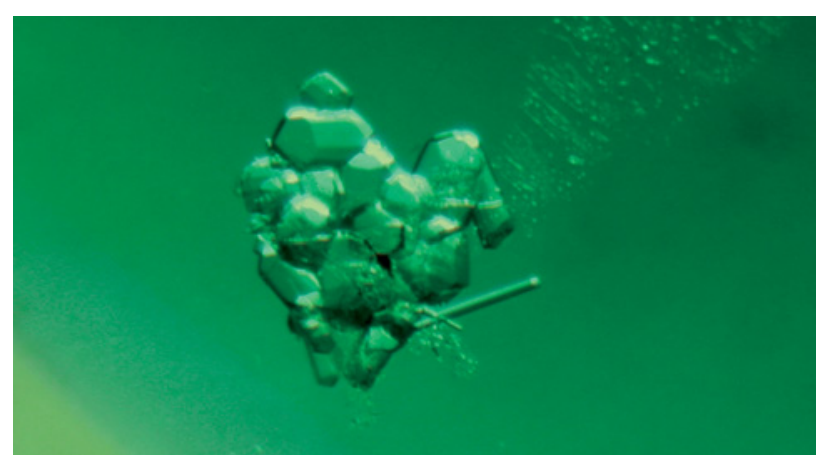

trace elements can provide supporting evidence for the Malossi product, but these criteria should not be relied on independently. Mid-IR spectroscopy can also be used to aid in the separation, as there are several bands related to $\mathrm{Cl}$ in the $3100-2500 \mathrm{~cm}^{-1}$ range.

Although Russian hydrothermal synthetic emeralds are not new to the 2000s, an excellent review article discussing their microscopic properties was published by Schmetzer et al. (2007).

Hydrothermally grown synthetic aquamarines, some violetish blue, were also reported in the 2000s as having been grown by Malossi in the Czech Republic (Adamo et al., 2008; see, e.g., figure 15). Just as with previously described synthetic aquamarine (Koivula and Kammerling, 1988) from Novosibirsk, Russia, that was marketed through the Tairus joint venture (Thailand-Russia), these new Malossi manufactured aquamarines also displayed characteristic

Figure 15. During the first decade of the 2000s, in addition to synthetic emeralds Malossi also produced hydrothermally grown synthetic aquamarines, such as the rough (14-16 g) and faceted (2.0-5.0 ct) material shown here. Photo by Alberto Malossi.

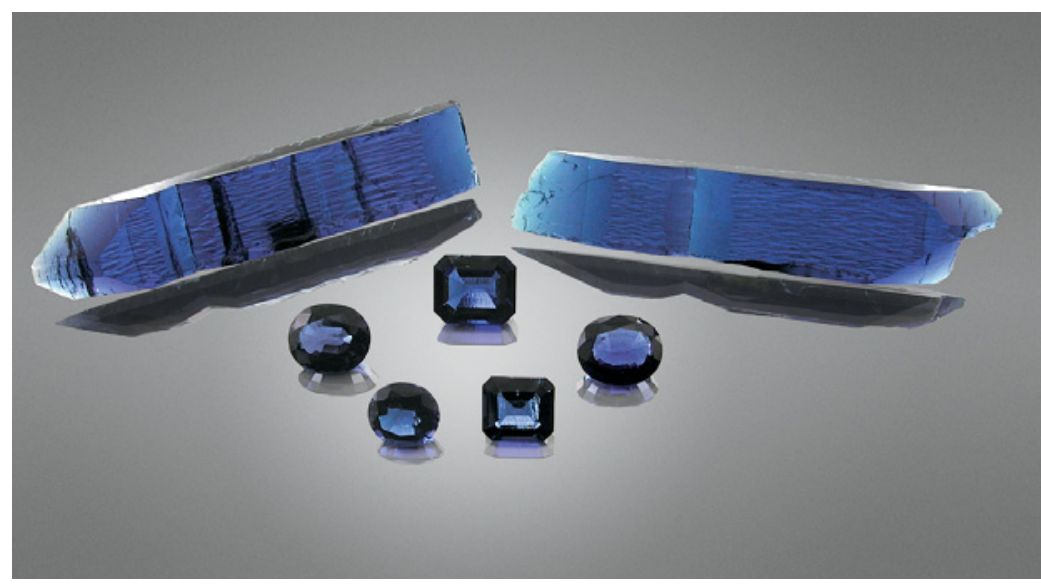




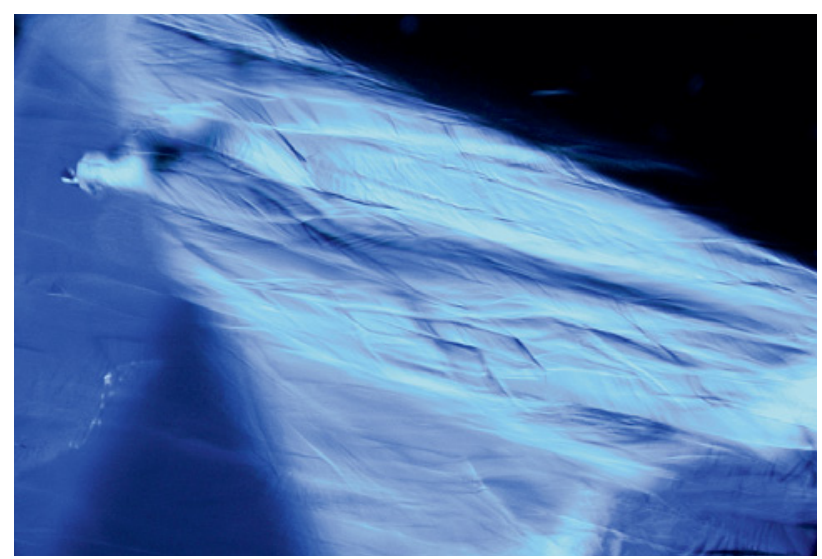

Figure 16. Like those previously produced in Russia, the Czech-Italian Malossi-manufactured blue beryls display characteristic roiled-to-angular structures or patterns of subgrain boundaries and intergrowths. Photomicrograph by Ilaria Adamo; magnified 25x.

roiled-to-angular growth structures or patterns of subgrain boundaries or intergrowths (figure 16).

Although hydrothermally grown synthetic red beryl was produced in earlier decades, the detailed descriptions by Shigley et al. (2001) and Fumagalli et al. (2003) are particularly useful in separating it from natural red beryl. Manufactured by the Institute of Crystallography and an affiliated company, Emcom Ltd., both located in Moscow, this material is produced under conditions similar to those used to grow other varieties of synthetic beryl. To give the red, pinkish red, and orange-red colors (figure 17), Co and $\mathrm{Mn}$ are introduced into the nutrient solution. RI and SG measurements were within published ranges for natural red beryl. Magnification revealed

Figure 17. Manufactured in Moscow, these hydrothermally grown orange-red and pinkish red synthetic beryls derive their color from cobalt (left and center, 1.08 and $1.95 \mathrm{~g}$ ) and manganese (right, $6.32 \mathrm{~g}$ ) introduced into the nutrient solution. Photo by Robert Weldon.

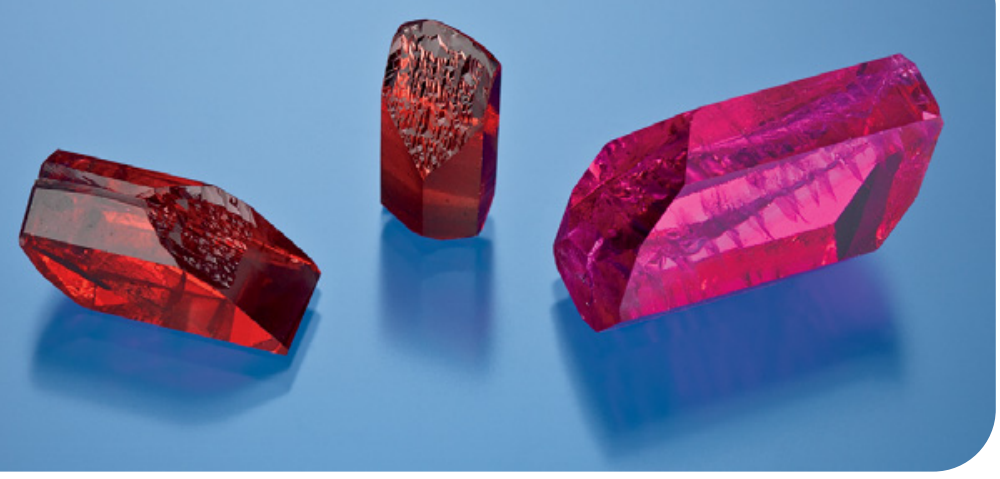

chevron-shaped growth zoning, typical of hydrothermal synthetic beryl products. Several absorption bands were seen between 530 and $590 \mathrm{~nm}$; these are due to $\mathrm{Co}^{2+}$ and are not observed in natural red beryl. Chemical analysis showed that $\mathrm{Co}$ and $\mathrm{Ni}$ were the two most diagnostic trace elements, as these elements are not seen in natural red beryl. Another diagnostic feature is an absorption band in the infrared between 4200 and $3200 \mathrm{~cm}^{-1}$. This band is related to water and is absent from natural red beryl, which formed in a pneumatolytic high-temperature igneous (rhyolitic) environment that contained very little water.

\section{SYNTHETIC JADEITE}

The production of intense green, highly translucent synthetic "Imperial" jadeite was perhaps one of the most interesting and exciting developments in the first decade of the 2000s. While the synthesis of jadeite had been attempted by General Electric for more than 20 years (Nassau and Shigley, 1987), it was not until this decade that a truly successful product was achieved (Moses, 2002). As shown in figure 18, the quality of this synthetic rivals that of the finest natural green jadeite. Most of the material is very slightly mottled in white and intense green, with the overall effect being a rich green color. Only one cabochon examined contained an inclusion-an irregular black patch that could not be identified (figure 19). The small number of samples seen had gemological properties that overlapped those of natural jadeite of similar color and translucency. Fortunately, there are obvious differences in the IR region (Cao et al., 2008). Since FTIR analysis is a standard technique used to check jadeite for polymer impregnation, it is doubtful that any of these syn-

Figure 18. During the past decade, General Electric grew extremely high-quality synthetic jadeite, as illustrated by these two cabochons (5.20 and $6.73 \mathrm{ct}$ ). Photo by Robert Weldon.

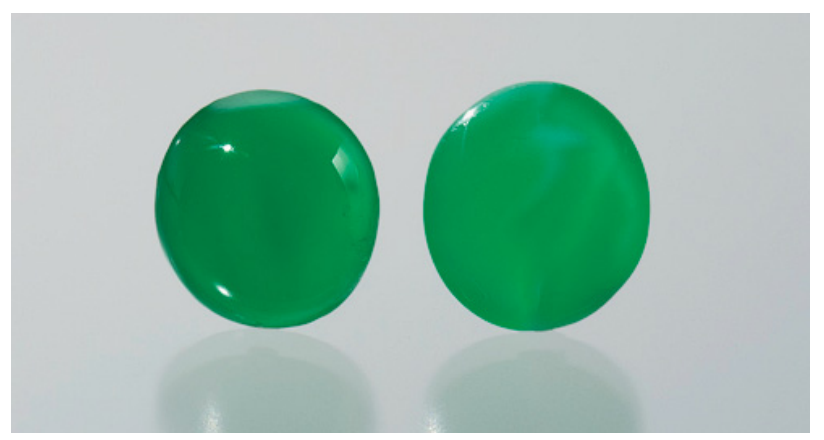




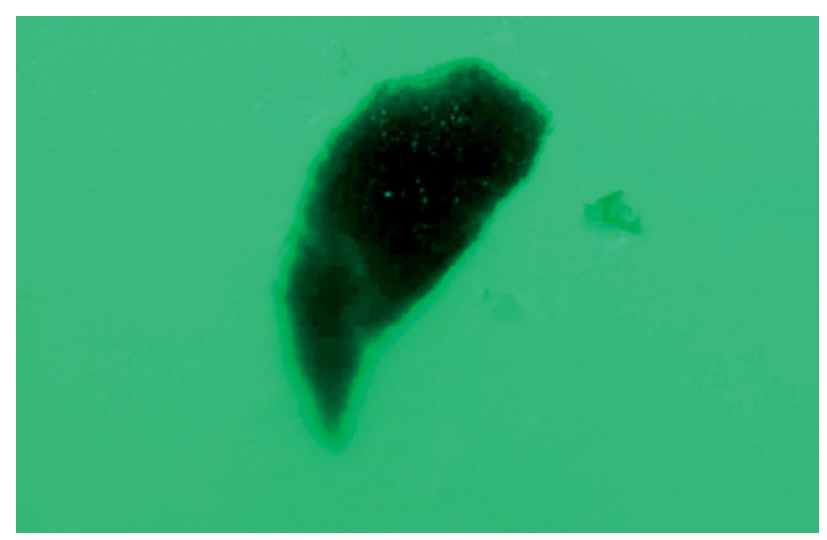

Figure 19. The only inclusion observed in the two cabochons of GE synthetic jadeite was this unidentifiable irregular dark spot. Photomicrograph by I. I. Koivula; magnified 20x.

thetic jadeite cabochons will be undetected in the laboratory if or when this synthetic is commercially manufactured and distributed (which, to the best of our knowledge, is not yet the case).

\section{SYNTHETIC QUARTZ}

Hydrothermal growth of synthetic quartz on prepared seed crystals was a significant synthesis technique throughout the 1990s. While synthetic amethyst (figure 20) is not a new development, a detailed study by Balitsky et al. (2004) compared the infrared absorption spectra of numerous synthetic amethyst samples grown from $\mathrm{K}_{2} \mathrm{CO}_{3}$ and $\mathrm{NH}_{4} \mathrm{~F}$ solutions, along with a limited number of Chinese and Japanese hydrothermal synthetics.

Absorption bands at $\sim 3595$ and $3543 \mathrm{~cm}^{-1}$ have diagnostic value in separating natural and synthetic amethyst (see also Karampelas et al., 2005). While the $3595 \mathrm{~cm}^{-1}$ band has not been observed in synthetic amethyst, it is occasionally also absent from natural material, which limits its diagnostic effectiveness. When the $3543 \mathrm{~cm}^{-1}$ band is found in amethyst grown in a near-neutral $\mathrm{NH}_{4} \mathrm{~F}$ solution (indicated by additional bands at 3680,3664 , and $3630 \mathrm{~cm}^{-1}$ ), synthetic origin is certain. The $3543 \mathrm{~cm}^{-1}$ band, however, is commonly seen in more commercially significant synthetic amethyst grown in alkaline $\mathrm{K}_{2} \mathrm{CO}_{3}$ solutions, and it has occasionally been observed in natural amethyst from a few localities. For the most part, then, these features are not independently conclusive of natural or synthetic origin in amethyst, but they provide supporting evidence for origin determination (Balitsky and Balitskaya, 2009). A combination of microscopic observations, such as growth features and inclusions, should be used in conjunction with these IR features.

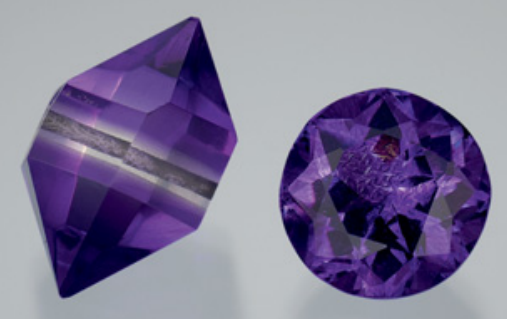

Figure 20. While synthetic amethyst, such as this $3.90 \mathrm{~g}$ crystal and $10.10 \mathrm{ct}$ round brilliant, was not new in the last decade, advances were made in the use of FTIR spectroscopy to identify it. Photo by Robert Weldon.

\section{SYNTHETIC ALEXANDRITE}

Synthetic alexandrite of high clarity is commonly grown by the Czochralski process, which was not new to the 2000s. Such material generally does not cause any real concern among gemologists, since we are immediately suspicious of any nearly flawless colored stone. Melt-grown synthetic alexandrites can be readily separated from natural stones by FTIR analysis (Stockton and Kane, 1988).

As with any gem material, however, unusual examples may occasionally appear. Some synthetic alexandrites contain odd-shaped "gas bubbles" (figure 21) that, on first observation, can appear very similar to the negative crystals seen in natural alexandrite (Mayerson and Kondo, 2005). While faceted synthetic alexandrites are often virtually flawless, cabochons usually contain at least a few easily observed gas bubbles that are useful in identification. However, if a few high-relief "negative crystals" are the only inclusions present, care should be exercised to make sure they are not the distorted gas bubbles found in a Czochralski-pulled synthetic.

\section{SYNTHETIC OPAL}

A nonphenomenal synthetic fire opal called Mexifire (figure 22) was one of the few new synthetic colored stones produced and marketed in the 2000s (Choudhary and Bhandari, 2008; Bhandari and Choudhary, 2010; Henn et al., 2010). While synthetic opal has been commercially produced since 1975, most of this material shows play-of-color. Mexifire does not, and its structure is reportedly similar to that of natural opal (i.e., composed of silica spheres); it also owes its orange color to traces of iron. One notable advantage to the synthetic material is that it does not appear to craze, as its natural counterpart often does. 


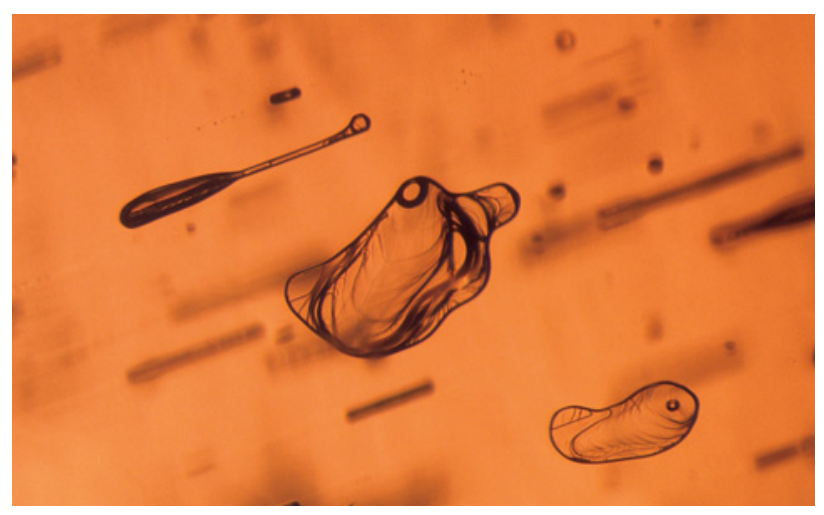

Figure 21. The distorted gas bubbles that sometimes occur in Czochralski melt-grown synthetic alexandrites can have the appearance of high-relief negative crystals. Such inclusions may be quite deceptive. Photomicrograph by I. I. Koivula; magnified 25×.

Gemological properties of the initial Mexifire product showed RI readings that were slightly lower (1.380-1.405) than those reported for natural fire opal (1.420-1.430). The SG (1.63-1.77) was also lower than what would be expected for natural fire opal ( 2.00). The Mexifire product has a zonal turbid structure, and minute pinpoints are scattered throughout the material (figure 22, right). Unlike synthetic opals from other manufacturers, the Mexifire synthetic opals do not show a characteristic "chicken wire" or columnar structure. Energy-dispersive X-ray fluorescence (EDXRF) spectroscopy showed traces of $\mathrm{Fe}$ and $\mathrm{Ca}$ in the Mexifire product, which is consistent with natural fire opal. While $\mathrm{Zr}$ has been used to impregnate and stabilize opal in the past, it was not detected in this material. IR spectroscopy showed an absorption hump at 4600-4300 $\mathrm{cm}^{-1}$ that is sometimes absent from natural opal. While this feature cannot provide proof of natural or synthetic origin, the absence of this feature may suggest natural material.

Since late 2009, the process has been modified such that the new Mexifire product has gemological properties much more like those of natural fire opal. While the microscopic properties of the two generations of material are similar, the new Mexifire synthetic opal has a consistent RI reading of 1.47 and an SG of 2.19. Although these measurements are not exactly the same as natural material, they are close enough to cause concern, and careful testing is required if an opal is suspect. Fortunately, the new Mexifire material shows a characteristic infrared spectrum that allows conclusive separation from natural opal. Features observed in the new generation of Mexifire opal are a weak hump at $\sim 5440$ $\mathrm{cm}^{-1}$, a sharp peak with a shoulder $\sim 4520 \mathrm{~cm}^{-1}$, an absorption band in the $4000-3250 \mathrm{~cm}^{-1}$ region, a weak shoulder at $2652 \mathrm{~cm}^{-1}$, and complete absorption of wavelengths below $2400 \mathrm{~cm}^{-1}$ (Bhandari and Choudhary, 2010).

While Mexifire synthetic opal is very similar to natural opal in many respects, careful RI and SG measurements should give a strong indicator of its synthetic origin. When identifying gem materials in this property range, it should be noted that manufactured glass is also a possibility.

\section{UNUSUAL SYNTHETICS}

Experimentation and failed laser development sometimes result in unusual synthetic gem materials. Such was the case with two materials reported in the 2000s.

A synthetic apatite (figure 23) with a color change from purple pink in incandescent light to violetish blue in fluorescent light was reported by McClure (2001). While most of the gemological properties were consistent with natural apatite, suspicion arose from an unusual spectrum (seen with a desk-model spectroscope) that was different from natural material. EDXRF analysis showed that the synthetic
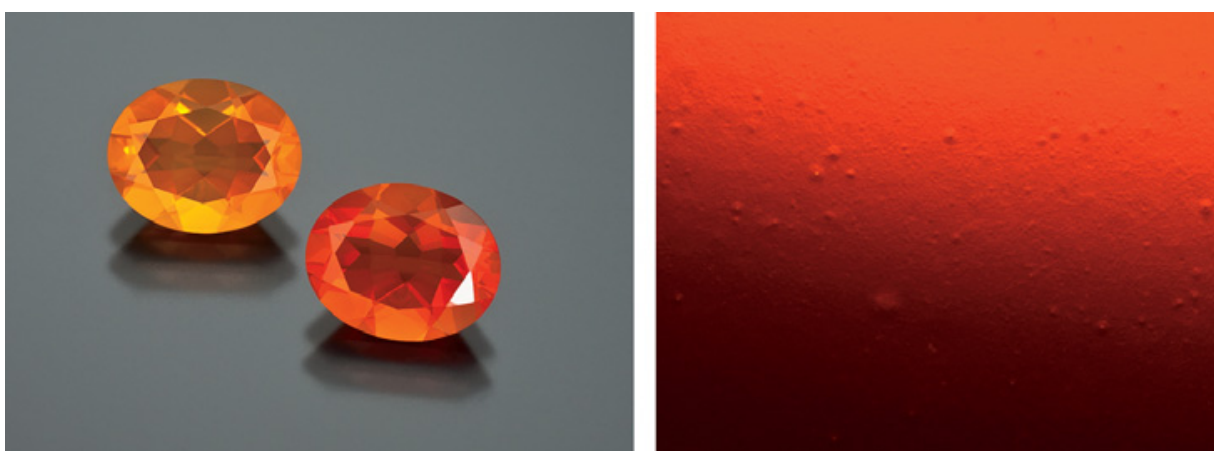

Figure 22. At 1.47 and $1.56 \mathrm{ct}$ (left), these two Mexifire synthetic opals show the color range and transparency of this nonphenomenal material. These synthetics commonly have a turbid appearance and minute pinpoints (right). Left photo by Robert Weldon; right photomicrograph by I. I. Koivula, magnified 60x. 

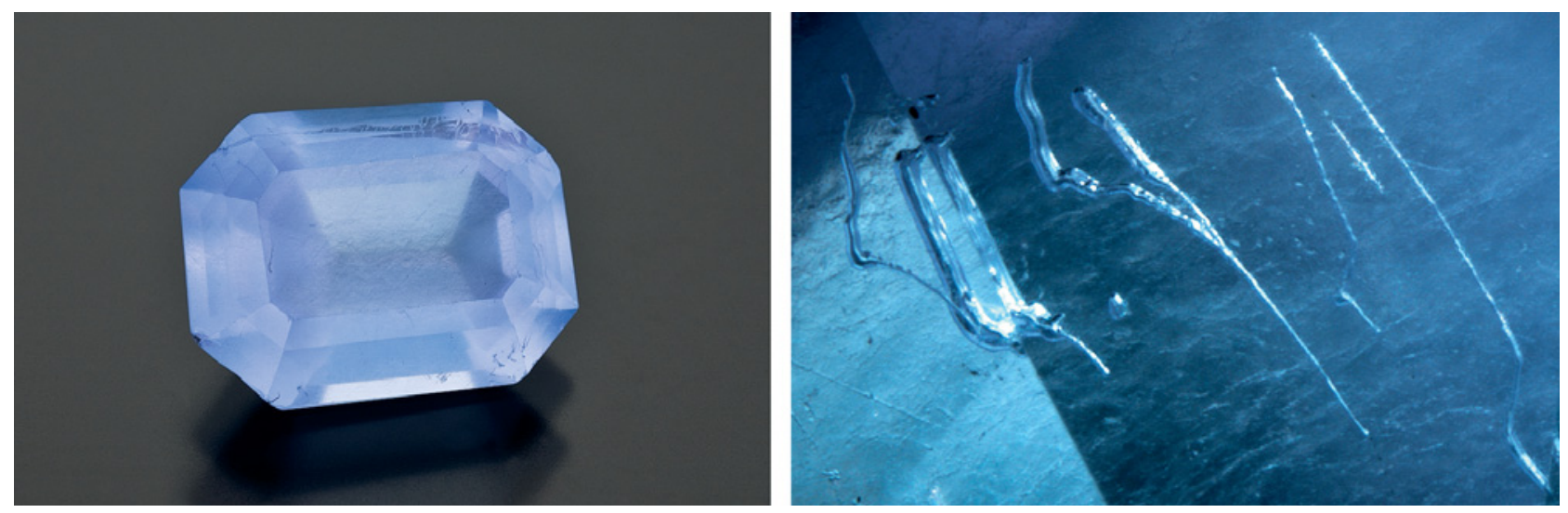

Figure 23. Significant amounts of neodymium and strontium were detected in this unusual $3.03 \mathrm{ct}$ color-change synthetic apatite. Magnification (right) revealed features that indicated synthetic origin, such as these elongated gas bubbles. Left photo by Robert Weldon; right photomicrograph by J. I. Koivula, magnified $30 \times$.

apatite contained a significant amount of neodymium and a small amount of strontium. Magnification revealed chevron-type growth and elongated gas bubbles, features that strongly supported a synthetic origin (figure 23, right). While synthetic apatite is an oddity in the gem world, it has previously been reported for laser applications (Koivula et al., 1992).

Another oddity reported in the early 2000s was the growth of synthetic topaz crystals up to $20 \mathrm{~g}$ (100 ct) in size (Lu and Balitsky, 2001). This may strike the reader as particularly unusual given the abundance of natural topaz in large sizes. The stated reason for growing this synthetic was to better understand crystal formation, morphology, and causes of color in natural pegmatitic topaz. This material was hydrothermally grown using crushed natural quartz and topaz dissolved in an aqueous fluoride-bearing fluid. Light gray to colorless crystals were produced as overgrowths on a natural topaz seed plate suspended in the nutrient solution. Experiments were then conducted to modify the color of the as-grown crystals. As is also the case with treated-color natural topaz, reddish brown was produced by ionizing irradiation (Balitsky et al., 2004) and blue was produced by high-energy electron irradiation with subsequent heat treatment (Lu and Balitsky, 2001). The gemological properties and Raman and FTIR spectra were within the ranges for natural material. Chemical analysis by EDXRF showed traces of germanium, nickel, and iron.

\section{CONCLUSION: PREDICTIONS FOR THE NEXT DECADE}

It is safe to predict that technology will continue to advance, and with that will come improvements in existing synthesis techniques and products. As with synthetic apatite and topaz, there will always be unusual materials produced with what appearnow-to have limited commercial potential. Such synthetics will surely arise from time to time and present their own unique gemological challenges. We believe, however, that the greatest advances in synthesis will continue to be focused on the most commercially important gems: diamond, emerald, ruby, and sapphire.

Currently, the vast majority of gem-quality synthetic diamonds are melee-size HPHT-grown material (Quinn, 2005; Kitawaki et al., 2008), which require care to identify. Eventually, the trade will have to decide at what point it is no longer economic to identify such small synthetic diamonds, especially if swift, accurate, and inexpensive testing methods are not developed.

Will the jewelry industry be ready for these developments? When you consider that many synthetic growth processes are more than a century old and still plague the trade, our preparedness must be questioned. If tradespeople continue to submit flamefusion synthetic rubies, sapphires, and spinels to gem laboratories for identification, then one must ask: How are they handling the thousands of carats of more technologically advanced flux-grown, hydrothermal, and Czochralski-pulled synthetics? We believe the answer will be found through gemological education. Over the next decade, every jeweler's goal should be to gain gemological expertise on a par with their "computer age" business skills. It is vital to have a sound working knowledge of the identifying characteristics for all synthetics, past and present. Such knowledge will also help the gemologist prepare for future developments. 


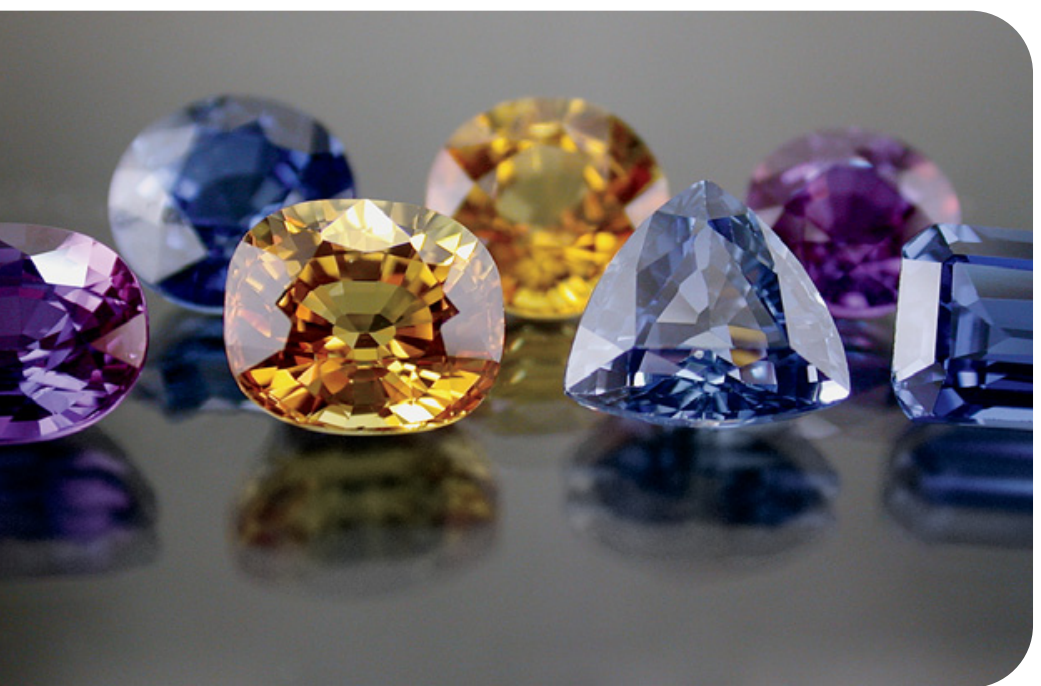

Figure 24. Purchased over the internet, these were advertised as heat-treated natural sapphires, but all turned out to be flame-fusion synthetics $(4.5-7.0 \mathrm{ct})$.

Photo by G. Roskin.

New treatment processes were by far the big news of the past decade. Because of that, today's experts too often expect sapphires to be beryllium treated, or diamonds to be HPHT treated. In Las Vegas in June 2010, a 1977 GIA classmate of one of the authors (GR) handed him a parcel of seven

\section{REFERENCES}

Adamo I., Pavese A., Prosperi L., Diella V., Merlini M., Gemmi M., Ajò D. (2005) Characterization of the new Malossi hydrothermal synthetic emerald. Ge G, Vol. 41, No. 4, pp. 328-338.

Adamo I., Pavese A., Prosperi L., Diella V., Ajò D., Gatta G.D., Smith C.P. (2008) Aquamarine, Maxixe-type beryl, and hydrothermal synthetic blue beryl: Analysis and identification. Ge)G, Vol. 44, No. 3, pp. 214-226.

Angus J.C. (1994) Development of low-pressure diamond growth in the United States. In K.E. Spear and J.P. Dismukes, Eds., Synthetic Diamond: Emerging CVD Science and Technology, John Wiley \& Sons, New York, pp. 21-39.

Badzian A., Badzian T. (1993) Diamond homoepitaxy by chemical vapor deposition. Diamond and Related Materials, Vol. 2, No. 2/4, pp. 147-157.

Balitsky V.S., Balitskaya O.V. (2009) The genetic approach for identification of varieties of crystalline and amorphous silica. Australian Gemmologist, Vol. 23, No. 11, pp. 500-508.

Balitsky V.S., Balitsky D.V., Bondarenko G.V., Balitskaya O.V. (2004) The $3543 \mathrm{~cm}^{-1}$ infrared absorption band in natural and synthetic amethyst and its value in identification. $G e G$, Vol. 40, No. 2, pp. 146-161.

Balitsky V.S., Balitsky D.V., Balitsky S.D., Aurisicchio C., Roma M.A. (2006) Silica and alumina transfer in supercritical aqueous fluids and growing of topaz monocrystals in them. Geochemistry International, Vol. 44, No 2, pp. 175-181.

Bates R. (2003) Wired cover spotlights synthetics. JCK, Vol. 174, No. 11, p. 46.

Bhandari R., Choudhary G. (2010) Update on Mexifire synthetic stones purchased over the Internet as heated natural sapphires (figure 24). Since they were advertised as heated, he assumed when he purchased them that the worst case scenario would be that they turned out to be beryllium diffused. After examination, worse news was evident: They all were flame-fusion synthetic sapphires, with not a heat-treated natural stone in the group.

\section{ABOUT THE AUTHORS}

Mr.Renfro (nathan.renfro@gia.edu) is staff gemologist, and Mr. Koivula is chief gemologist, at the GIA Laboratory in Carlsbad, California. Dr. Wang is director of research at the GIA Laboratory in New York. Mr. Roskin is based in Downingtown, Pennsylvania, and is editor of the online magazine Roskin Gem News Report.

\section{ACKNOWLEDGMENTS}

The authors are indebted to Dr. Ilaria Adamo, of the Università degli Studi di Milano, and Robert Weldon, of GIA Carlsbad, for help in preparing certain sections and for performing archival research for this article. fire opal. Get G, Vol. 46, No. 4, pp. 287-290.

Bundy F.P., Hall H.T., Strong H.M., Wentorf R.H. (1955) Manmade diamonds. Nature, Vol. 176, p. 51.

Butler J.E., Woodin R.L. (1993) Thin film diamond growth mechanisms. Philosophical Transactions of the Royal Society of London A, Vol. 342, pp. 209-224.

Butler J.E., Mankelevich Y.A., Cheesman A., Ma J., Ashfold M.N.R. (2009) Understanding the chemical vapor deposition of diamond: Recent progress. Journal of Physics: Condensed Matter, Vol. 21, Art. 364201 (20 pp.).

Cao S.-M., Qi L.-J.,Guo Q.-H., Zhong Z.-Q., Qiu Z.-L., Li Z.-G. (2008) Study on the vibrational spectra characterization of synthetic jadeite jade made by General Electric Company. Spectroscopy and Spectral Analysis, Vol. 28, No. 4, pp. 847-851.

Chadwick K. (2008) Lab Notes: HPHT-treated CVD synthetic diamond submitted for Dossier grading. Ge G, Vol. 44, No. 4, pp. 365-367.

Chadwick K.M., Breeding C.M. (2008) Lab Notes: First CVD synthetic diamond submitted for Dossier grading. $G \uplus G$, Vol. 44, No. 1, pp. 67-69.

Choudhary G. (2005) Gem News International: Yellow hydrothermal synthetic sapphires seen in India. Ge G, Vol. 41, No. 2, p. 182 .

(2008) Gem News International: Purplish blue synthetic quartz. Ge G, Vol. 44, No. 4, pp. 377-379.

Choudhary G., Bhandari R. (2008) A new type of synthetic fire opal: Mexifire. Ge)G, Vol. 44, No. 3, pp. 228-233. 
Davis J. (2003) The new diamond age. Wired, Vol. 11, No. 9, pp. 96-146.

Davis R.F. (1993) Diamond Films and Coatings: Development, Properties, and Applications. Noyes Publications, Park Ridge, NJ, $421 \mathrm{pp}$.

Doering P.J., Linares R.C. (1999) Large area single crystal CVD diamond: Properties and applications. Proceedings of Applied Diamond Conference/Frontier Carbon Technology Joint Conference 1999, Tsukuba, Japan, pp. 32-35.

Fumagalli M., Prosperi L., Pavese A., Bordiga S. (2003) Natural versus hydrothermal synthetic Russian red beryl: Chemical composition and spectroscopic measurements. Journal of Gemmology, Vol. 28, No. 5, pp. 291-301.

Grahm D.D. (2003) A company called LifeGem gives memorials for the dead a high-tech twist. Colored Stone, Sept./Oct., pp. 50, $52-53$.

Gübelin E.J., Koivula J.I. (1986) Photoatlas of Inclusions in Gemstones. ABC Edition, Zurich, Switzerland.

- (2005) Photoatlas of Inclusions in Gemstones, Vol. 2. Opinio Publishers, Basel, Switzerland.

- (2008) Photoatlas of Inclusions in Gemstones, Vol. 3. Opinio Publishers, Basel, Switzerland.

Henn U., Wehr K., and Milisenda C.C. (2010) Synthetischer Feueropal-_Mexifire." Gemmologie: Zeitschrift der Deutschen Gemmologischen Gesellschaft, Vol. 59, No. 1/2, pp. 47-50.

Jang-Green H., Befi R. (2007) Lab Notes: Glass-filled synthetic ruby. $G \uplus G$, Vol. 43, No. 3, pp. 250-251.

Kane R.E. (2009) Seeking low-cost perfection: Synthetic gems. Elements, Vol. 5, No. 3, pp. 169-174.

Karampelas S., Fritsch E., Zorba T., Paraskevopoulos K.M., Sklavounos S. (2005) Distinguishing natural from synthetic amethyst: The presence and shape of the $3595 \mathrm{~cm}^{-1}$ peak. Mineralogy and Petrology, Vol. 85, No. 1/2, pp. 45-52.

Kiefert L., Hänni H.A., Schmetzer K. (2004) Gem News International: Synthetic Verneuil corundum with unusual color zoning. $G \uplus G$, Vol. 40, No. 4, pp. 354-355.

Kiffer A.D. (1956) Synthesis of diamond from carbon monoxide. Tonawanda Laboratories, Linde Air Products, June 6.

Kitawaki H., Abduriyim A., Okano M. (2008) Identification of melee-sized synthetic yellow diamonds in jewelry. $G \uplus G$, Vol. 44, No. 3, pp. 202-213.

Kitawaki H., Abduriyim A., Kawano J., Okano M. (2010) Gem News International: Treated CVD-grown pink synthetic diamond melee. $G \uplus G$, Vol. 46, No. 1, pp. 68-69.

Koivula J.I., Kammerling R.C. (1988) Gem News: Unusual synthetic beryls from the Soviet Union. Ge G, Vol. 24, No. 4, p. 252.

Koivula J.I., Kammerling R.C., Fritsch E. (1992) Gem News: Update on crystal growth. GetG, Vol. 28, No. 4, p. 277.

- (1993) Gem News: Color-zoned synthetic blue quartz. Ge) G, Vol. 29, No. 2, pp. 140-141.

Koivula J.I., Tannous M., Schmetzer K. (2000) Synthetic gem materials and simulants in the 1990s. $G \uplus G$, Vol. 36, No. 4, pp. 360-379.

Koivula J.I., Inns A., Shen A.H.-T. (2008) Lab Notes: Green synthetic sapphire with vibrant blue inclusions. $G \uplus G$, Vol. 44, No. 1, pp. 72-73.

Laurs B.M., Overton T.W. (2003) Gem News International: LifeGem synthetic diamonds. Ge G, Vol. 39, No. 1, p. 62.

Linares R.C., Doering P.J. (1999) Properties of large single crystal diamond. Diamond and Related Materials, Vol. 8, No. 2/5, pp. 909-915.

Lu T., Balitsky V.S. (2001) Gem News International: Synthetic topaz crystals. $G \uplus G$, Vol. 37, No. 4, pp. 339-341.

Martineau P.M., Lawson S.C., Taylor A.J., Quinn S.J., Evans D.J.F., Crowder M.J. (2004) Identification of synthetic diamonds grown using chemical vapor deposition (CVD). Ge G, Vol. 40, No. 1, pp. 2-25.

Mayerson W.M., Kondo D. (2005) Lab Notes: Unusual synthetic alexandrite. $G \uplus G$, Vol. 41, No. 3, pp. 256-257.

McClure S.F. (2001) Lab Notes: Synthetic apatite. $G \uplus G$, Vol. 37, No. 1, p. 57.

Miyatake H., Arima K., Maida O., Teraji T., Ito Y. (2007) Further improvement in high crystalline quality of homoepitaxial CVD diamond. Diamond and Related Materials, Vol. 16, No. 4/7, pp. 679-684.

Moses T. (2002) Lab Notes: High-quality synthetic jadeite from General Electric. $G \uplus G$, Vol. 38, No. 2, pp. 166-167.

Nassau K. (1990) Synthetic gem materials in the 1980s. Ge G, Vol. 26, No. 1, pp. 50-63.

Nassau K., Shigley J.E. (1987) A study of the General Electric synthetic jadeite. Ge G, Vol. 23, No. 1, pp. 27-35.

Quinn E.P. (2005) Lab Notes: Small synthetic diamonds. $G \uplus G$, Vol. 41, No. 4, pp. 345-346.

Roskin G. (2003) Identifying CVD synthetic diamond. JCK, Vol. 174 , No. 11, pp. 46-49.

(2004) Tucson 2004: A gemstone cornucopia. JCK, Vol. 175, No. 4, pp. 102-108.

Schmetzer K., Bernhardt H.-J., Schwarz D. (2007) Vanadium- and copper-bearing Tairus hydrothermally-grown synthetic emerald: An update on microscopic properties. Journal of the Gemmological Association of Hong Kong, Vol. 28, pp. 71-75.

Shigley J.E., McClure S.F., Cole J.E., Koivula J.I., Lu T., Elen S., Demianets L.N. (2001) Hydrothermal synthetic red beryl from the Institute of Crystallography, Moscow. Ge G, Vol. 37, No. 1, pp. 42-55.

Shigley J.E., Abbaschian R., Clarke C. (2002) Gemesis laboratorycreated diamonds. $G \uplus G$, Vol. 38, No. 4, pp. 301-309.

Shigley J.E., McClure S.F., Breeding C.M., Shen A.H.-T. Muhlmeister S.M. (2004) Lab-grown colored diamonds from Chatham Created Gems. Ge G, Vol. 40, No. 2, pp. 128-145.

Stockton C.M., Kane R.E. (1988) The distinction of natural from synthetic alexandrite by infrared spectroscopy. $G \uplus G$, Vol. 24, No. 1, pp. 44-46.

Spear K.E., Dismukes J.P. (1994) Synthetic Diamond: Emerging CVD Science and Technology. John Wiley \& Sons, New York, $663 \mathrm{pp}$.

Tallaire A., Achard J., Sussmann R.S., Silva F., Gicquel A. (2005) Homoepitaxial deposition of high-quality thick diamond films: Effect of growth parameters. Diamond and Related Materials, Vol. 14, No. 3/7, pp. 249-254.

Wang W. (2009) Lab Notes: Diamond-Fancy red, irradiated and annealed. $G \uplus G$, Vol. 45, No. 3, p. 208.

Wang W., Johnson P. (2010) Lab Notes: Red CVD synthetic diamond with multiple treatments. $G \uplus G$, Vol. 46, No. 1, pp. $52-54$.

Wang W., Moe K.S. (2010) Lab Notes: CVD synthetic diamond over one carat. $G \uplus G$, Vol. 46, No. 2, pp. 143-144.

Wang W., Moses T.M. (2010) Lab Notes: Large yellow-orange HPHT synthetic diamond. Ge G, Vol. 46, No. 4, pp. 299-300.

Wang W., Moses T., Linares R.C., Shigley J.E., Hall M., Butler J.E. (2003) Gem-quality synthetic diamonds grown by a chemical vapor deposition (CVD) method. $G \uplus G$, Vol. 39, No. 4, pp. 268-283.

Wang W., Tallaire A., Hall M.S., Moses T.M., Achard J., Sussmann R.S., Gicquel A. (2005) Experimental CVD synthetic diamonds from LIMHP-CNRS, France. Ge G, Vol. 41, No. 3, pp. 234-244.

Wang W., Hall M.S., Moe K.S., Tower J., Moses T.M. (2007) Latestgeneration CVD-grown synthetic diamonds from Apollo Diamond Inc. Ge G, Vol. 43, No. 4, pp. 294-312.

Wang W., Doering P., Tower J., Lu R., Eaton-Magaña S., Johnson P., Emerson E., Moses T.M. (2010) Strongly colored pink CVD lab-grown diamonds. $G \uplus G$, Vol. 46, No. 1, pp. 4-17.

Yan C.-S., Mao H.-K., Li W., Qian J., Zhao Y.S., Hemley R.J. (2004) Ultrahard diamond single crystals from chemical vapor deposition. Physica Status Solidi (a), Vol. 201, No. 4, pp. R25-R27. 